\title{
The impact of model for end-stage liver disease (MELD) score on liver transplant outcomes in low volume liver transplantation center: single center experience
}

\author{
Shin Hoo Pyo ${ }^{1}$, Doojin $\mathrm{Kim}^{2}$, Dooho Lee ${ }^{2}$, Sang Tae $\mathrm{Choi}^{2}$, Yeon Ho Park ${ }^{2}$ \\ ${ }^{1}$ Department of Medicine, Gachon University College of Medicine, Incheon, Korea \\ ${ }^{2}$ Division of Transplantation, Department of Surgery, Gachon University Gil Medical Center, Incheon, Korea
}

Background: In June of 2016, the model for end-stage liver disease (MELD) score was employed in Korea instead of the ChildTurcotte-Pugh (CTP) score. This study compared the outcomes of deceased donor liver transplantation (DDLT) before and after MELD system.

Methods: From January 2014 to December 2018, 48 patients were underwent DDLT in a single center. Patients were divided into two groups according in a same time period (2.5 years) from MELD allocation time (2016 June). Laboratory data and clinical outcomes were collected and analyzed retrospectively.

Results: There were 22 in the pre-MELD group and 26 in the MELD group. There was no difference in age, sex, ABO type, etiology for liver transplantation, CTP score, operation time, cold ischemic time, and amount of red blood cell transfusion. However, the MELD score of the two groups differed significantly $(36.2 \pm 4.9$ in the MELD group, $27.7 \pm 11.8$ in the pre-MELD group, $P<0.001)$. MELD group revealed longer intensive care unit stay and hospital stay than pre-MELD group $(11.2 \pm 9.5$ vs. $5.7 \pm 4.5, P=0.018$; $36.8 \pm 26$ vs. $22.8 \pm 9.3, \mathrm{P}=0.016)$. Mean follow-up time was 32.8 months and 1 -year survival rate was lower in MELD group $(61.5 \%$ vs. $86.4 \%)$ although statistically insignificant $(P=0.056)$.

Conclusions: After MELD allocation, high MELD patients increased in DDLT and consequently needed had longer recovery time. Also they might have negative results in survivals. According to a small volume center's experience, these problems were related with severe organ shortage in Korea rather than MELD.

Corresponding author: Doojin Kim

E-mail: drkdj@gilhospital.com

\section{(c) The Korean Society for Transplantation}

This is an Open Access article distributed under the terms of the Creative Commons Attribution Non-Commercial License (http://creativecommons.org/licenses/by-nc/4.0/) which permits unrestricted non-commercial use, distribution, and reproduction in any medium, provided the original work is properly cited. 